\title{
Trauma Exposure, Posttraumatic Stress Disorder and Alcohol Use Disorder among Females in Jos, North Central Nigeria
}

Suwa Goden Goar ${ }^{1 *}$, Friday Philip Tungchama ${ }^{1}$, Maigari Yusuf Taru ${ }^{1}$, Charles Nnameka Nwoga ${ }^{1}$, Mike Bankat ${ }^{1}$, Moses David Audu ${ }^{1}$ and Francis John Davou²

${ }^{1}$ Department of Psychiatry, University of Jos, Plateau State, Nigeria

${ }^{2}$ Department of Psychiatry, University of Abuja, Nigeria

\begin{abstract}
Objective: The study was undertaken to examine the association between PTSD and Sociodemographic factors. It also determined the association between trauma exposure with and without PTSD and Alcohol Use Disorders.

Method: The cross-sectional descriptive study was carried out from March to July, 2017. Multistage sampling technique was employed to select participants who consented aged 18 years and above after ethical clearance was obtained. The data was collected using Sociodemographic questionnaire, OSLO-3 social support scale, AUDIT and PTSD Modules of MINI.

Results: A total of 272 females with an age range of 18 to 60 years responded. The mean age was $28.8 \pm 8.6$ years. Majority $112(41.2 \%)$ were in the age group of $25-34$ years. Most of them were never married $168(61.8 \%)$, protestant $151(55.5 \%)$ and had secondary education $97(35.7 \%)$. About half of them were employed $148(54.4 \%)$ with $167(61.4 \%)$ of them on an average income of 20,000 naira or less. Perceived social support was reported as good by $133(41.5 \%)$ and poor by $159(58.5)$. fifty seven $(21.0 \%)$ of participants fulfilled the criteria for PTSD. Majority $188(69.9 \%)$ reported at least one life time traumatic experience. Sociodemographic variables significantly associated with PTSD are; marital status $(x 2=11.671, D F=2, P=0.003)$, educational level $(x 2=11.485, D F=3, P=0.009)$ and social support $(X 2=5.391, D F=1, P=0.020)$. Of those who reported exposure to traumatic event $131(69.7 \%)$ did not develop PTSD but $57(30.3 \%)$ developed PTSD. Sixty nine (36.2\%) engaged in binge drinking and $68(36.2 \%)$ had alcohol use disorders; all were significantly associated with exposure to trauma with or without PTSD.

Conclusion: Prevention and intervention efforts should be broadened to include those who are exposed to trauma with and without PTSD seeking treatment in the community and to screen for alcohol use disorders especially among women who were previously married with lower levels of education.
\end{abstract}

Keywords: Women; Trauma exposure; PTSD; Sociodemographic; Alcohol Use Disorders

\section{Introduction}

Globally epidemiological studies have shown that traumatic experiences which could either be in the form of an event or series of events and response to an event or events and physical health, psychiatric morbidity especially posttraumatic stress disorder, depression as well as alcohol use disorders are interrelated $[1,2]$. Although, exposure to traumatic life events is common throughout the world, it is more worrisome in a patriarchal society like Nigeria where women are treated with gender subordination which has subjected them to experiencing chronic traumas. The various forms of trauma against women in Nigeria include; female child labor, wife battery, female genital mutilation, violence from in-laws and sexual relationships, work place sexual harassment, negative cultural attitudes and degrading traditional practices among others [3].

It has been reported that $60.7 \%$ of men and $51.2 \%$ of women would experience at least one potentially traumatic event in their lifetime [4,5]. Similarly in a study carried out in a community in Kashmir, South Asia, a life time prevalence of $58.69 \%$ was found for any traumatic experience [6]. On the contrary Breslau et al. found that $90 \%$ of participants in a community survey reported that they have experienced at least one traumatic event at some point in their life [6]. The differentials could be accounted for by the level of trauma exposure in armed conflicts, methods used and sociocultural factors. Most epidemiological studies in Nigeria did not examine life time prevalence of women exposed to traumatic events but not diagnosed with PTSD in the community but rather to specific traumatic experiences among Internally Displaced Persons, armed conflict victims, child birth and students [7-9,32,33].

Women experiences of trauma have been linked to a variety of negative mental health consequences including Posttraumatic Stress Disorder (PTSD) [10]. PTSD is a condition characterized by repeated episodes of reliving the events in the form of dreams, flash backs or intrusive memories often accompanied by emotional numbness and dissociation. It may involve detachment from others, anhedonia and avoidance of activities that remind the victim of the event. Estimates from community studies have shown that women suffered more from PTSD compared with men $[4,7,8]$. It has been suggested that women may be more vulnerable to PTSD because they are more likely to experience trauma within established relationships or their traumatic exposures are more chronic than those experienced by men [11,12]. This is because victims are often still living with their perpetrators leading to high amount of stress, fear and anxiety including PTSD [3].

*Corresponding author: Suwa Goden Goar, Department of Psychiatry University of Jos, Plateau State, Nigeria, Tel: +2348130291664; E-mail: goarsuwa@yahoo.com

Received: June 28, 2018; Accepted: July 23, 2018; Published: July 30, 2018

Citation: Goar SG, Tungchama FP, Taru MY, Nwoga CN, Bankat M, et al (2018) Trauma Exposure, Posttraumatic Stress Disorder and Alcohol Use Disorder among Females in Jos, North Central Nigeria. J Psychiatry 21: 453. doi:10.4172/2378-5756.1000453

Copyright: $\odot 2018$ Goar SG, et al. This is an open-access article distributed under the terms of the Creative Commons Attribution License, which permits unrestricted use, distribution, and reproduction in any medium, provided the original author and source are credited 
One of the ways to cope with PTSD symptoms and other stressors as well as the related negative and physiological states is the use of psychoactive substances to halt or suppress it [13]. Studies have suggested that the psychoactive substances are chosen based on their psychopharmacological effects to fit the specific symptoms they are intended to alleviate $[13,14]$. For example, alcohol a central nervous system depressant has been used to reduce anxiety. When this is successful, the consumption of alcohol is negatively reinforced and may lead to alcohol use disorders [15]. Consequently, trauma exposure and PTSD are associated with high rates of alcohol use disorders in both western and developing countries $[8,16,17]$. Hazardous alcohol use or dependence is the most frequent comorbidity with PTSD among women. In the US National Comorbidity Survey, PTSD prevalence of $26.2 \%$ was reported in women who have either alcohol abuse or dependence compared with the general population [18]. Similarly, Davou et al found an association between alcohol abuse or dependence and PTSD in a post conflict community in Plateau State, Nigeria [16]. PTSD in women tends to be chronic and persistent which have been accounted for by lack of sufficient social support, the use of maladaptive coping strategies such as consumption of alcohol in large quantity to manage trauma related symptoms [12]. On the other hand, longitudinal studies have shown that PTSD and alcohol use are reciprocally related in time forward because if PTSD is not treated it may lead to greater alcohol use $[19,20]$.

Researchers have found that women who live in impoverished settings where life is characterized with experiences of violence, unemployment, gender inequality and alcohol abuse have increased vulnerability to posttraumatic stress disorder [21,22]. The presence of persistence psychological distress can exacerbate alcohol use [23]. Moreover, hazardous use of alcohol in women is associated with numerous disease and behavioral outcomes such as fetal alcohol spectrum disorder, HIV risk behavior and gender based violence $[24,25]$. The comorbidity of PTSD and alcohol related disorders is a double-tragedy in a resource scarce setting where they may often go undetected and even when detected the public health care system may be ill-equipped to provide comprehensive treatment.

Extant literatures revealed that alcohol use disorders and PTSD may be associated with poorer physical and psychological health and poorer functioning compared to those with either alone [24,25]. In order to develop effective interventions for PTSD in women, further understanding is needed regarding the factors associated with it. This study was undertaken to examine the relationship between PTSD and Sociodemographic factors/social support. It also determined the association between trauma exposure with and without PTSD and Alcohol Use Disorder.

\section{Materials and Methods}

The study was conducted in Jos North Local Government Area of Plateau state in North Central Nigeria from March to July, 2017 after ethical clearance was obtained. It was a community-based descriptive cross-sectional study with sample size of 272 . The sample size was determined by the Kish formula for cross sectional studies. Formula $\mathrm{n}=\mathrm{Z} 2 \mathrm{pq} / \mathrm{d} 2$

Where: $\mathrm{Z}=$ standard score variance $=1.96$ which correspond to $95 \%$ confidence level

$\mathrm{P}=$ prevalence rate of $23 \%, \mathrm{q}=$ proportion of failure $=1-\mathrm{p}, \mathrm{d}=$ degree of accuracy desired estimated at $0.05(5 \%), \mathrm{n}=1.962 \times 0.23 \times$ $0.77 / 0.052=272$.
Multistage sampling technique was employed to select respondents aged 18 years and above who consented. In the first stage Jos North LGA was purposively selected. Simple random sampling was used to select two wards from the twelve wards and one community from each ward that was selected. One eligible adult was interviewed at the time of data collection from each household. If there were more than one adult in a household, balloting was then used for selection.

The data was collected using Sociodemographic questionnaire, Alcohol Use Disorders Identification Test (AUDIT), OSLO-3 social support scale and PTSD Modules of Mini-International NeuroPsychiatric Interview (MINI). The Sociodemographic questionnaire elicited variables such as age, sex, marital status, religion, employment status, average monthly income and level of education.

Alcohol use was determined by "Do you ever drink alcohol nowadays, including drinks you brew or make at home?" Those who answered Yes to this question were administered Alcohol Use Disorder Identification Test (AUDIT). The AUDIT is a cross-culturally validated instrument for assessment of alcohol use in the general population to identify currently harmful or hazardous drinking and probable dependence. The AUDIT has a total score of 40 , those who scored 8 or more were considered as having at least hazardous drinking (here after referred to as Alcohol Use Disorders). Binge drinking was assessed by asking "How often do you have four or more drinks on one occasion?" Never $=0$, less than monthly $=1$, monthly $=2$, weekly $=3$, daily or almost daily $=4$. These responses were further categorized into two; no binge drinking if scored zero and binge drinking for those who scored 1 to 4. The OSLO 3-item social support scale was used to assess perceived social support. It is a 3-item questionnaire with the score ranging from 3 to 14 . Based on the mean of the total score it was dichotomized into two variables: scores below the mean was considered as "poor social support" while scores equal to the mean or above was considered as "good social support". OSLO 3- item social support scale has been validated in Nigeria [26]. The MINI is a brief, structured interview for the major Axis 1 psychiatric disorders in DSM-IV and ICD-10 that is widely used [27]. It has good validity and reliability making it ideal for cross-cultural studies [28]. The MINI has been used in many studies in Nigeria $[8,16]$. Trauma exposure in this study refers to individuals who have ever experienced or witnessed or had to deal with an extremely traumative event that included actual or threatened death or serious injury to themselves or someone else in their entire life while growing up as well as adulthood.

The data analysis was done using Statistical Package for Social Sciences version 20 (SPSS-20) soft wares. The P-value of $\leq 0.05$ at $95 \%$ Confidence Interval was considered statistically significant. Simple descriptive analysis was used to present the results. Chi-square test was computed for associations between categorical variables and those with significant associations were further subjected to logistic regression.

\section{Results}

A total of 272 females with an age range of 18 to 60 years responded. The mean age was $28.8 \pm 8.6$ years. Majority $112(41.2 \%)$ were in the age group of 25-34 years. Most of them were never married 168(61.8\%), protestant $151(55.5 \%)$ and had secondary education $97(35.7 \%)$. About half of them were employed 148(54.4\%) with 167(61.4\%) of them on an average income of 20,000 naira or less. Perceived social support was reported as good by 133(41.5\%) and poor by 159(58.5). fifty seven $(21.0 \%)$ of participants fulfilled the criteria for PTSD. Majority $188(69.9 \%)$ reported at least one life time traumatic experience while 84(30.1\%) had none (Table 1$)$. 
Citation: Goar SG, Tungchama FP, Taru MY, Nwoga CN, Bankat M, et al. (2018) Trauma Exposure, Posttraumatic Stress Disorder and Alcohol Use Disorder among Females in Jos, North Central Nigeria. J Psychiatry 21: 453. doi:10.4172/2378-5756.1000453

Sociodemographic variables significantly associated with PTSD are; marital status $(\chi 2=11.671, \mathrm{DF}=2, \mathrm{P}=0.003)$ with the married and never married less likely to develop PTSD, educational level $(\chi 2=11.485$, $\mathrm{DF}=3, \mathrm{P}=0.009)$ with lower levels of education with higher odds of developing PTSD and social support $(\chi 2=5.391, \mathrm{DF}=1, \mathrm{P}=0.020)$ with poor support having higher odds for PTSD (Table 2).
Of those who reported exposure to traumatic event 131(69.7\%) did not develop PTSD but 57(30.3\%) developed PTSD. Sixty nine (36.2\%) engaged in binge drinking $(\chi 2=7.075, \mathrm{DF}=1, \mathrm{P}=0.008)$ and $68(36.2 \%)$ had alcohol use disorders $(\chi 2=14.130, \mathrm{DF}=1, \mathrm{P}=0.001)$, all were significantly associated with exposure to trauma with or without PTSD (Tables 3 and 4).

\begin{tabular}{|c|c|c|}
\hline Variables Age group & Number (272) & Percentage (100) \\
\hline $18-24$ & 96 & 35.3 \\
\hline $25-34$ & 112 & 41.2 \\
\hline $35-44$ & 44 & 16.2 \\
\hline $45-60$ & 20 & 7.4 \\
\hline \multicolumn{3}{|c|}{ Marital Status } \\
\hline Never married & 168 & 61.8 \\
\hline Married & 74 & 27.2 \\
\hline Previously Married & 30 & 11 \\
\hline \multicolumn{3}{|c|}{ Educational level } \\
\hline No formal education & 23 & 8.5 \\
\hline Primary & 61 & 22.4 \\
\hline Secondary & 97 & 35.7 \\
\hline Tertiary education & 91 & 33.5 \\
\hline \multicolumn{3}{|c|}{ Religion } \\
\hline Protestant & 151 & 55.5 \\
\hline Catholic & 80 & 29.4 \\
\hline Islam & 23 & 8.5 \\
\hline Others & 18 & 6.6 \\
\hline \multicolumn{3}{|c|}{ Employment Status } \\
\hline Unemployed & 124 & 45.6 \\
\hline Employed & 148 & 54.4 \\
\hline \multicolumn{3}{|c|}{ Monthly Income in Naira } \\
\hline$\leq 20,000$ & 167 & 61.4 \\
\hline$\geq 20,000$ & 105 & 38.6 \\
\hline \multicolumn{3}{|c|}{ Social support } \\
\hline Poor & 159 & 58.5 \\
\hline Good & 113 & 41.5 \\
\hline \multicolumn{3}{|c|}{ PTSD Prevalence } \\
\hline No & 215 & 79 \\
\hline Yes & 57 & 21 \\
\hline \multicolumn{3}{|c|}{ Traumatic Exposure life time } \\
\hline Exposed & 188 & 69.9 \\
\hline None & 84 & 30.1 \\
\hline
\end{tabular}

Table 1: Sociodemographic characteristics, Social Support and PTSD Prevalence.

\begin{tabular}{|c|c|c|c|c|c|c|c|c|}
\hline \multirow{3}{*}{ Variables Age group } & \multicolumn{2}{|c|}{ PTSD } & \multirow{2}{*}{ Total } & \multirow{3}{*}{ Chi-square } & \multirow{3}{*}{ DF } & \multirow{3}{*}{$\begin{array}{l}\text { P-value }(\leq \\
0.05)\end{array}$} & \multirow{3}{*}{ OR } & \multirow{3}{*}{$95 \%$ C-I } \\
\hline & Yes & No & & & & & & \\
\hline & $\mathrm{n}=57$ & $n=215(\%)$ & $\mathrm{N}=272$ & & & & & \\
\hline $18-24$ & $17(17.7)$ & $79(82.3)$ & $96(100)$ & 3.008 & 3 & 0.378 & & \\
\hline $25-34$ & $23(20.5)$ & $89(79.5)$ & $112(100)$ & & & & & \\
\hline $35-44$ & $10(22.7)$ & $34(77.3)$ & $44(100)$ & & & & & \\
\hline $45-60$ & $7(35.0)$ & $13(65.0)$ & $20(100)$ & & & & & \\
\hline \multicolumn{9}{|c|}{ Marital Status } \\
\hline Never Married & $27(16.1)$ & $141(83.9)$ & $168(100)$ & 11.671 & 2 & $\times 0.003$ & 0.297 & $0.122-0.719$ \\
\hline Married & $17(23.0)$ & $57(77.0)$ & $74(100)$ & & & & 0.403 & $0.155-1.048$ \\
\hline $\begin{array}{l}\text { Previously Married(divorced, separated \& } \\
\text { widows) }\end{array}$ & $13(43.3)$ & $17(56.7)$ & $30(100)$ & & & & 1 & \\
\hline \multicolumn{9}{|c|}{ Education Level } \\
\hline No formal education & $10(43.5)$ & $13(56.5)$ & $23(100)$ & 11.485 & 3 & ${ }^{\times} 0.009$ & 2.147 & $0.762-6.051$ \\
\hline Primary & $16(26.2)$ & $45(73.8)$ & $61(100)$ & & & & 1.313 & $0.597-2.886$ \\
\hline Secondary & $13(13.4)$ & $84(86.6)$ & $97(100)$ & & & & 0.639 & $0.284-1.438$ \\
\hline
\end{tabular}


Citation: Goar SG, Tungchama FP, Taru MY, Nwoga CN, Bankat M, et al. (2018) Trauma Exposure, Posttraumatic Stress Disorder and Alcohol Use Disorder among Females in Jos, North Central Nigeria. J Psychiatry 21: 453. doi:10.4172/2378-5756.1000453

Page 4 of 6

\begin{tabular}{|c|c|c|c|c|c|c|c|c|}
\hline Tertiary & $18(19.8)$ & $73(80.2)$ & $91(100)$ & & & & 1 & \\
\hline \multicolumn{9}{|c|}{ Religion } \\
\hline Protestants & $32(21.2)$ & $119(78.8)$ & $151(100)$ & 0.497 & 3 & 0.92 & & \\
\hline Catholic & $18(22.5)$ & $62(77.5)$ & $80(100)$ & & & & & \\
\hline Islam & $4(17.4)$ & $19(82.6)$ & $23(100)$ & & & & & \\
\hline Others & $3(16.7)$ & $15(83.3)$ & $18(100)$ & & & & & \\
\hline \multicolumn{9}{|c|}{ Emploment Status } \\
\hline Unemployed & $25(20.2)$ & $99(79.8)$ & $124(100)$ & 0.087 & 1 & 0.768 & & \\
\hline Employed & $32(21.6)$ & $116(78.4)$ & $148(100)$ & & & & & \\
\hline \multicolumn{9}{|c|}{ Monthly Income (Naira) } \\
\hline$\leq 20,000$ & $37(22.2)$ & $130(77.8)$ & $167(100)$ & 0.376 & 1 & 0.54 & & \\
\hline$\geq 20,000$ & $20(19.0)$ & $85(81.0)$ & $105(100)$ & & & & & \\
\hline \multicolumn{9}{|c|}{ Social Support } \\
\hline Poor & $41(25.8)$ & $118(74.2)$ & $159(100)$ & 5.391 & 1 & ${ }^{\times} 0.020$ & 2.104 & $1.084-4.083$ \\
\hline Good & $16(14.2)$ & $97(85.8)$ & $113(100)$ & & & & 1 & \\
\hline
\end{tabular}

Table 2: Relationship between Sociodemographic factors, Social Support and PTSD.

\begin{tabular}{|c|c|c|}
\hline \multicolumn{1}{|c|}{ Variables } & Number (188) & \multicolumn{2}{|c|}{ Percentage (100) } \\
\hline \multicolumn{2}{|c|}{ Trauma Exposure } \\
\hline Exposed No PTSD & 131 & 57 \\
\hline Exposed with PTSD & Binge Drinking & \\
\hline No & 119 & 30.3 \\
\hline Yes & 69 & 36.7 \\
\hline No & Alcohol use disorders & \\
\hline Yes & 120 & 63.3 \\
\hline
\end{tabular}

Table 3: Trauma Exposure with and without PTSD and Alcohol Use Disorders.

\begin{tabular}{|c|c|c|c|c|c|c|c|c|}
\hline \multirow{2}{*}{ Variables } & \multicolumn{2}{|c|}{ Alcohol use disorders } & \multirow{2}{*}{ Total } & \multirow{2}{*}{ Chi-square } & \multirow{2}{*}{ DF } & \multirow{2}{*}{$P$-value $(\leq 0.05)$} & \multirow{2}{*}{ OR } & \multirow{2}{*}{$95 \% \mathrm{C}-\mathrm{I}$} \\
\hline & No & Yes & & & & & & \\
\hline \multicolumn{9}{|c|}{ Trauma Exposure } \\
\hline Exposed /No PTSD & $95(79.2)$ & $25(20.8)$ & $120(100)$ & 14.13 & 1 & 0.001 & 1 & \\
\hline Exposed /PTSD & $36(52.9)$ & $32(47.1)$ & $68(100)$ & & & & 0.424 & $0.224-0.804$ \\
\hline \multicolumn{9}{|c|}{ Binge drinking } \\
\hline Exposed/No PTSD & $91(76.5)$ & $28(23.5)$ & $119(100)$ & 7.075 & 1 & 0.008 & 1 & \\
\hline Exposed/PTSD & $40(58.0)$ & $29(42.0)$ & $69(100)$ & & & & 0.296 & $0.155-0.566$ \\
\hline
\end{tabular}

Table 4: Association between trauma exposure with and without PTSD and alcohol use disorders.

\section{Discussion}

The $69.9 \%$ prevalence of life time exposure to at least one traumatic experience found in this study is similar to previous researches $[7,18]$. This may due to the protracted ethno-religious conflicts within the North central Nigeria that has led to mass traumatization of its citizenry [7]. In addition, considering the peculiarities of a patriarchal society like Nigeria where various forms of violence against women still thrives may be responsible [3]. The need for assessing Life time prevalence of specific types of traumatic experiences among women in Nigeria especially in the central region is suggested.

The prevalence of PTSD in this study was $21.0 \%$ and it compares well with $15.9 \%$ found among control group in a comparative study by Maigari et al. in Zawan community [8]. However, among the trauma exposed with and without PTSD in the current study a prevalence rate of $30.3 \%$ was found. This is lower compared to previous studies carried out in some communities in Jos and its suburbs which range from $57.3 \%$ to $68.4 \%[7,8]$, though these studies were conducted in communities that had severely suffered armed conflict violent. Nevertheless, the prevalence of PTSD found in this study is considered high. The high prevalence rate may be conceptualized based on the fact that in a hegemonic masculine society women are often exposed to pretraumatic factors that favor the development of PTSD. For instance, negative cultural attitudes and degrading traditional practices, widow's rites, denial of female education, gender driven poverty, and polygamy among others are inimical to their psychological well-being [3]. Furthermore, women experience intimate partner violence with in a relationship more than men and often victims still live with their perpetrators leading to high amount of stress, fear and anxiety $[3,11,12]$

In a study done by Maigari et al. it was found that previously married women were more susceptible to develop PTSD compared to those who were married [8]. Similarly, this study found that the previously married were more likely to have PTSD. It has been asserted that previously married is associated with low level of social support, independence and self-esteem which make them vulnerable to PTSD. This suggests that marriage confers some level of social support. Social support refers to the function and quality of social relationships and may affect the way one copes with stress. It may act as buffer and can reduce or even prevent PTSD from occurring [29,30]. The association between poor social support and PTSD found in the current study further supported this assertion. 
Having lower level of education is a known risk factor for PTSD [31-33]. Similarly, a significant relationship between lower levels of education and PTSD was found. Educational level may indirectly influence the availability of economic resources, social status, health behavior and social network. Therefore, women with higher educational levels may use better coping methods because they have access to more resources that serve as a buffer against PTSD. There was no significant association between age group and PTSD and this is consistent with the research carried out by Maigari et al. in the suburb of Jos [8]. This outcome may be as a result of exposure to different traumatic events of equal magnitude across the age groups in the study sample. Other Sociodemographic variables that were not associated with PTSD in the current study were; employment status and religion. This is in consonance with a previous study conducted in a rural community in Plateau state [8]. Studies have revealed that the co-existence of violence and poverty increased vulnerability to PTSD [22,23]. However, this study did not find significant relationship between monthly income and PTSD as against previous study carried out among victims of violent ethno-religious conflict in Barkin-Ladi, North Central Nigeria [8]. The possible explanation for this may be the differences in the study setting.

The findings from the current study are consistent with previous research that demonstrated a relationship between trauma exposure, PTSD and problematic alcohol consumption among women [10,29]. It has been found that women who used less effective coping styles such as emotion-and-avoidance coping strategies is associated with alcohol use disorders [29]. Other explanation for this is that women who engage in binge and hazardous drinking may be at greater risk of experiencing certain traumatic events such as rape and sexual assault which may lead to PTSD. Although trauma exposed individual may not meet the diagnostic criteria for PTSD, they may be engaging in binge and hazardous alcohol use to cope with negative affect and this is associated with numerous mental and physical health problems [13-16].

This study is not without limitations because we rely on participants retrospective reporting of traumatic events and symptoms leading to under or over reporting which may affect the actual prevalence of PTSD among women in the community. The research was confined to Jos metropolis and outcome may not be the true reflection of the prevalence of PTSD across the population in Nigeria. Therefore, a study with robust sample size cutting across the geopolitical regions of the country needs to be carried out. Nevertheless, the strength of the study lies on the fact that it is the first community based-survey among women exposed to traumatic experiences with and without PTSD and its association with binge drinking and other forms of Alcohol Use Disorders.

\section{Conclusion}

In conclusion the prevalence of PTSD in the study sample was high and it was significantly associated with poor social support, previously married (divorced, separated and widows) and educational level. Exposure to trauma with and without PTSD was associated with binge drinking and alcohol use disorders. Therefore, it is necessarily important for prevention and intervention efforts to be broadened to include those who are exposed to trauma with and without PTSD seeking treatment in the community.

\section{Acknowledgement}

The authors wish to sincerely appreciate volunteer workers of Quintessential Healthcare Center Jos (a non for profit governmental organization who assisted in data collection. We also thank the Wards Heads and Community Youth Leaders for their unflinching support during the survey.

\section{Conflict of Interest}

None

\section{Reference}

1. Catani C, Jacob N, Schauer E, Kohila M, Neuner F (2008) Family violence, war and natural disasters: a study of the effects of extreme stress on childrens' mental health in srilanka. BMC Psychiatry 8: 33.

2. Porter M, Haslam N (2005) Predisplament and postdisplacement factors associated with mental health of refugees and internally displaced persons: a meta-analysis. JAMA 294: 602-612.

3. Ruth AA, ljere IN (2018). Psycho-social traumatic events among women in Nigeria. Madridge J AID 1: 17-28.

4. Kessler RC, Sonnega A, Bromet E, Hughes M, Nelson CB (1995) Posttraumatic stress disorder in the National Comorbidity Survey. Arch Gen Psychiatr 52: 1048-1060.

5. Punamaki RL, Komproe IH, Qouta S, Elmasri M, TVM de Jong J (2005) The role of peritraumatic dissociation and gender inthe association between trauma and mental health in a Palestinian community sample. Am J Psychiatr 162 545-551.

6. Breslau N, Kessler RC, Chilcoat HD, Schultz LR, Davis GC (1998) Traumatic and posttraumatic stress disorder in the community. Arch Gen Psychiatr 55:626-632.

7. Tagurum YO, Chirdan OO, Obindo T, Bello DA, Afolaranmi TO (2015) Prevalence of violence and symptoms of Posttraumatic stress disorder among victims of ethno-religious conflict in Jos, Nigeria. J Psychiatry 18:178.

8. Maigari YT, Moses DA, Tungchama FP, Davou FJ, Goar SG (2017) Posttraumatic stress disorder in Dogonahawa and Zawan, North-Centra Nigeria, Four-years after communal violence: prevalence and risk factors. JMSCR 5: 17231-17240.

9. Agbir TM, Audu MD, Obindo JT, Davou FJ, Gyang BA, et al. (2016) Depression among Internally Displaced Persons in Riyom, Plateau State, North Central Nigeria. J Medical Res Pract 4: 13-17.

10. Kachadourian LK, Pilver CE, Potenza MN (2014) Trauma, PTSD and Binge and Hazardous Drinking Among women and Men: Findings from National Study. J Psychiatr Res 55: 35-40.

11. Kimerling R, Weitlauf JC, Iverson KM, Karpenko JA, Jain S (2013) Gender issues in PTSD. In M. J. Friedman, T.M. Keane and P.A. Resick (eds) Handbook of PTSD. Science and Practice. New York: Guilford Press.

12. Olff M, Langeland W, Draijer N, Gersons BPR (2007) Gender differences in Posttraumatic stress disorder. Psychological Bulletin 133: 183-204.

13. Khantzian EJ (2003) The Self-Medication Hypothesis Revisited: The dually dianosed patient. Primary Psychiatry 10: 53-54.

14. McFarlane AC (1998) Epidemiological evidence about the relationship between PTSD and alcohol abuse: The nature of the association. Addict Behav 23: 813-826.

15. Stewart SH, Conrod PJ, Samoluk S, Pihl RO, Dongier M (2000) Posttraumatic stress disorder symptoms and situation-specific drinking in women substance abusers. Alcohol Treat Quatr 18: 31-47.

16. Davou FJ, Armiyau AY, Tungchama FP, Maigari YT, Goar SG, et al. (2018) Psychiatric Morbidity among victims of violent ethno-religious conflicts in BarkinLadi, North Central Nigeria, five years after: prevalence and sociodemographic correlates. Psychol Psychology Res Int J 2018 3: 000168.

17. Kessler RC, Nelson CB, McGonagle KA, Edlund MJ, Frank RG, et al. (1996) The epidemiology of co-occuring addictive and mental disoders: implications for prevention and service utilization. Arch Gen Psychiatr 66: 17-31.

18. Hofman SG, Richey JA, Kashdan TB, McKnight PE (2009) Anxiety disorders moderate the association between externalizing problems and substance use disorders: data from the National Comorbidity Survey-revised. J Anxiety Disord 23: 529-534.

19. Boscarino JA, Kichmen HI, Hoffman SN, Sartorius J, Adams RE, et al. (2011) PTSD and alcohol use after world trade center attacks: a longitudinal study. $J$ Trauma Stress 24: 515-525.

20. McCart NK, Zalac K, Kofler MJ, Smith DW, Sauders BE, et al. (2012) Longitudinal examination of PTSD symptoms and problems alcohol use as risk factors for adolescent victimization. J Cli Child Adolesc Psychol 41: 822-836. 
Citation: Goar SG, Tungchama FP, Taru MY, Nwoga CN, Bankat M, et al. (2018) Trauma Exposure, Posttraumatic Stress Disorder and Alcohol Use Disorder among Females in Jos, North Central Nigeria. J Psychiatry 21: 453. doi:10.4172/2378-5756.1000453

21. Wechsberg WM, Myers B, Reed E, Carney T, Emmanuel AN, et al. (2013) Substance use, gender inequity, violence and sexual risk among couples in Cape Town. J Health Sex 15: 1-16.

22. Ozler B (2007) Not separate, not equal: poverty and inequality in post-apartheid South Africa. Econ Dev Cult Change 55: 487-529.

23. Watt MH, Ranby KW, Meade CS, Sikkema KJ, McFarlane JC, et al. (2012) Posttraumatic stress disorder symptoms mediate the relationship between traumatic experiences and drinking behaviour among women attending alcohol serving venues in South African township. J Stud Alcohol Drugs 73: 540.

24. Schneider M, Norman R, Parry C, Bradshaw D, Pluddermann A (2007) Collaboration SACRA: estimating the burden of diseas attributable to alcohol use in South Africa in 2000. S Afr Med J 97: 664-672.

25. May PA, Blankenship J, Marals AS, Gossage JP, Kalberg WO, et al. (2013) Maternal alcohol consumption producing fetal alcohol spectrum disorders (FASD): quantity, frequency and timing of drinking. Drug Alcohol Depend 133: 502-512.

26. Abiola T, Udofia U, Zakari M (2013) Psychometric Properties of the 3-item OSLO Social Support Scale among Clinical Students of Bayero University Kano, Nigeria. Malays J Psychiatry 22: 32-41.

27. Sheehan DV, Lecrubrier $Y$, Sheehan KH, Amorim P, Janavs J, et al. (1998)
The Mini-International Neuropsychiatric Interview (MINI): The development and validation of a structured diagnostic psychiatric interview for DSM-IV and ICD10. J Clin Psychiatr 59: 22-33.

28. Sheehan DV, Lecrubrier Y, Sheehan KH, Janavs J, Weller E, et al. (1997) The validity of the mini international neuropsychiatric interview (MINI) according to the SCID-P and its reliability. European Psychiatr 12:232-241.

29. Kaysen D, Atkins DC, Simpson TL, Stappenbeck CA, Blayney A, et al. (2014) Proximal Relationship between symptoms and drinking among female college students: Results from daily monitoring study. Psychol Addict Behav 28: 62-73.

30. Dar KA, Igbal N, Prakash A, Paul MA (2018) PTSD and depression in Adults survivors of flood fury in Kashmir: The payoffs of social support. Psychiatry Research 261: 449-455.

31. Xue C, Ge Y, Tang B, Liu Y, Kang P, et al. (2015). A Meta-Analysis of Risk Factors for Combat related PTSD among Military Personnel and Veterans. PloS ONE 10: e0120270.

32. Adewuya A, Ologun Y, Ibigbami O (2006) Post-traumatic stress disorder after childbirth in Nigerian women: prevalence and risk factors. BJOG 113: 284-288.

33. Nwoga CN, Audu MD, Obembe A (2016) Prevalence and correlates of posttraumatic stress disorder among medical students in the University of Jos. Niger J Clin Pract 19: 595-599. 